\title{
NUMERICAL SIMULATION ON LAMINAR CONVECTION FLOW AND HEAT TRANSFER OVER A NON-ISOTHERMAL HORIZONTAL PLATE
}

\author{
Asish Mitra ${ }^{1}$ \\ ${ }^{1}$ Associate Prof. and HOD, Basic Science and Humanities Department, College of Engineering \& Management, \\ Kolaghat, East Midnapur, India
}

\begin{abstract}
A numerical algorithm is presented for studying laminar convection flow and heat transfer over a non-isothermal horizontal plate. plate temperature $T_{w}$ varies with $x$ in the following prescribed manner:

$$
T_{w}=T_{1}+C x^{n}
$$

where $C$ and $n$ are constants. By means of similarity transformation, the original nonlinear partial differential equations of flow are transformed to a pair of nonlinear ordinary differential equations. Subsequently they are reduced to a first order system and integrated using Newton Raphson and adaptive Runge-Kutta methods. The computer codes are developed for this numerical analysis in Matlab environment. Velocity, and temperature profiles for various Prandtl number and $n$ are illustrated graphically. Flow and heat transfer parameters are derived. The results of the present simulation are then compared with experimental data in literature with good agreement.
\end{abstract}

Keywords: Free Convection, Heat Transfer, Non-isothermal Horizontal Plate, Matlab, Numerical Simulation.

\section{List of Symbols}

$\mathrm{a}_{1}, \mathrm{a}_{2}$ initial values eq (26)

$\mathrm{C}_{\mathrm{f}, \mathrm{x}}$ friction coefficient, dimensionless

$\mathrm{f}$ function defined in eq (6)

$\mathrm{k}$ thermal conductivity, W/m.K

$\mathrm{Nu}_{\mathrm{x}}$ Nusselt number at $\mathrm{x}$, dimensionless

Pr Prandtl number, dimensionless

$\mathrm{q}_{\mathrm{w}}$ heat flux of the plate, $\mathrm{W} / \mathrm{m}^{2}$

$\mathrm{Re}_{\mathrm{x}}$ Reynolds number at $\mathrm{x}$, dimensionless

$\mathrm{T}$ temperature, $\mathrm{K}$

$\mathrm{T}_{\mathrm{w}}$ surface temperature, $\mathrm{K}$

$\mathrm{T}_{1}$ free streams temperature, $\mathrm{K}$

$\mathrm{u}$ velocity component in $\mathrm{x}, \mathrm{m} / \mathrm{s}$

$\mathrm{u}_{1}$ free stream velocity in $\mathrm{x}, \mathrm{m} / \mathrm{s}$

$\mathrm{v}$ velocity component in $\mathrm{y}, \mathrm{m} / \mathrm{s}$

$\mathrm{x}$ coordinate from the leading edge, $\mathrm{m}$

$\mathrm{y}$ coordinate normal to plate, $\mathrm{m}$

$\mathrm{z}_{1}, \mathrm{z}_{2}, \mathrm{z}_{3}, \mathrm{z}_{4}, \mathrm{z}_{5}$ variables, eq (23)

\section{Greek Symbols}

$\theta$ function defined in eq (18), dimensionless

$\beta$ coefficient of thermal expansion, $1 / \mathrm{K}$

$\delta$ boundary layer thickness, $\mathrm{m}$

$\alpha$ thermal diffusivity, $\mathrm{m}^{2} / \mathrm{s}$

$\mu$ dynamic viscosity, N.s $/ \mathrm{m}^{2}$

$v$ kinematic viscosity, $\mathrm{m}^{2} / \mathrm{s}$

$\eta$ similarity variables, eq (7)

$\tau$ shear stress, $\mathrm{N} / \mathrm{m}^{2}$ $\tau_{\mathrm{s}} \quad$ wall shear stress, $\mathrm{N} / \mathrm{m}^{2}$

$\psi$ stream function, $\mathrm{m}^{2} / \mathrm{s}$

$\rho$ density, $\mathrm{kg} / \mathrm{m}^{3}$

$\rho_{\infty}$ free stream density, $\mathrm{kg} / \mathrm{m}^{3}$

\section{INTRODUCTION}

There have been a number of studies on natural convection over an isothermal horizontal plate due to its relevance to a variety of industrial applications and naturally occurring processes, such as solar collectors, pipes, ducts, electronic packages, airfoils, turbine blades etc. The earliest analytical investigation was a similarity analysis of the boundary layer equations by Blasius [1]. Many other methods of attack are chronicled in the text books by Meksyn [2] and Rosenhead [3]. The problem is also discussed in several text books [4-11].

In the present numerical investigation, a simple accurate numerical simulation of laminar free-convection flow and heat transfer over an isothermal horizontal plate is developed.

The paper is organized as follows: Mathematical model of the problem, its solution procedure, development of code in Matlab, interpretation of the results, comparison with experimental data. 


\section{MATHEMATICAL MODEL}

We consider the flow of a fluid of velocity $u_{1}$ over a nonisothermal horizontal plate where plate temperature $\mathrm{T}_{\mathrm{w}}$ varies with $\mathrm{x}$ in the following prescribed manner:

$$
T_{w}=T_{1}+C x^{n}
$$

where $\mathrm{C}$ and $\mathrm{n}$ are constants. We assume the natural convection flow to be steady, laminar, two-dimensional, having no dissipation, and the fluid to be Newtonian with constant properties, including density, with one exception: the density difference $\rho-\rho_{\infty}$ is to be considered since it is this density difference between the inside and the outside of the boundary layer that gives rise to buoyancy force and sustains flow, known in the literature as Boussinesq approximation. We take the direction along the plate to be $x$, and the direction normal to surface to be $y$, as shown in Fig 1 .

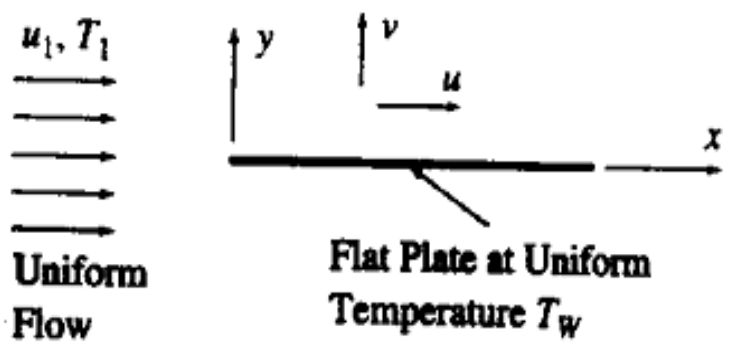

Fig. 1 Physical Model and its coordinate system

The equations governing the flow are

$$
\begin{aligned}
& \frac{\partial u}{\partial x}+\frac{\partial v}{\partial y}=0 \\
& u \frac{\partial u}{\partial x}+v \frac{\partial u}{\partial y}=v \frac{\partial^{2} u}{\partial y^{2}} \\
& u \frac{\partial T}{\partial x}+v \frac{\partial T}{\partial y}=\alpha \frac{\partial^{2} T}{\partial y^{2}}
\end{aligned}
$$

The boundary conditions on the solution are:

$$
\text { At } y=0: u=v=0, \quad T=T_{w}+C x^{n}
$$

For large $\mathrm{y}: \mathrm{u} \rightarrow \mathrm{u}_{1}, \mathrm{~T} \rightarrow \mathrm{T}_{1}$

The continuity equation (1) is automatically satisfied through introduction of the stream function:

$$
u \equiv \frac{\partial \psi}{\partial y} \quad v \equiv-\frac{\partial \psi}{\partial x}
$$

A similarity solution is possible if

$$
\psi=u_{1} \sqrt{\frac{v x}{u_{1}}} f(\eta)
$$

where, $\eta$ is the similarity variable

$$
\eta=\frac{y}{x} \sqrt{\operatorname{Re}_{x}}=y \sqrt{\frac{u_{1}}{v x}}
$$

The basic form of the velocity profiles at different values of $\mathrm{x}$, as shown in Fig 2, are all the same.

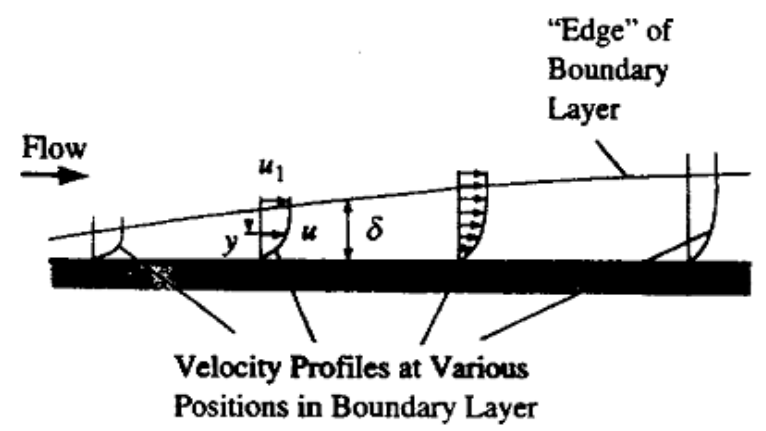

Fig. 2 Velocity profiles at various positions in the boundary layer over a flat plate

The velocity profiles at all points in the boundary layer are assumed as follows:

$$
\frac{u}{u_{1}}=\operatorname{function}\left(\frac{y}{\delta}\right)
$$

The boundary layer assumptions indicate that:

$$
\frac{\delta}{x}=o\left(\frac{1}{\sqrt{\mathrm{Re}_{x}}}\right)
$$

Therefore, the similar velocity profile assumptions given in $\mathrm{Eq}(8)$ can be rewritten as

$$
\begin{aligned}
& \frac{u}{u_{1}}=\operatorname{function}\left(\frac{y}{x} \sqrt{\mathrm{Re}_{x}}\right) \\
& =\operatorname{function}\left(\sqrt{\frac{u_{1}}{v x}}\right)=\operatorname{function}(\eta)
\end{aligned}
$$

Hence, the velocity profile can be uniquely determined by the similarity variable $\eta$, which depends on both $\mathrm{x}$ and $\mathrm{y}$.

From equations (5) through (7), we get

$$
u=\frac{\partial \psi}{\partial y}=\frac{\partial \psi}{\partial \eta} \frac{\partial \eta}{\partial y}=u_{1} \sqrt{\frac{v x}{u_{1}}} \frac{d f}{d \eta} \sqrt{\frac{u_{1}}{v x}}=u_{1} \frac{d f}{d \eta}
$$


And

$$
\begin{aligned}
& v=-\frac{\partial \psi}{\partial x}=-\frac{\partial \psi}{\partial \eta} \frac{\partial \eta}{\partial x}=-\left(u_{1} \sqrt{\frac{v x}{u_{1}}} \frac{d f}{d x}+\frac{u_{1}}{2} \sqrt{\frac{v}{u_{1} x}} f\right) \\
& =\frac{1}{2} \sqrt{\frac{v u_{1}}{x}}\left(\eta \frac{d f}{d \eta}-f\right)
\end{aligned}
$$

By differentiating the velocity components, it may also be shown that

$$
\begin{aligned}
& \frac{\partial u}{\partial x}=-\frac{u_{1}}{2 x} \eta \frac{d^{2} f}{d \eta^{2}} \\
& \frac{\partial u}{\partial y}=u_{1} \sqrt{\frac{u_{1}}{v x}} \frac{d^{2} f}{d \eta^{2}} \\
& \frac{\partial^{2} u}{\partial y^{2}}=\frac{u_{1}^{2}}{v x} \frac{d^{3} f}{d \eta^{3}}
\end{aligned}
$$

Substituting these expressions into eq (2), we then obtain (with a prime denoting differentiation with respect to $\eta$ )

$$
2 f^{\prime \prime \prime}+f f^{\prime \prime}=0
$$

Hence the velocity boundary layer problem is reduced to an ordinary differential equation (16). This confirms the assumptions that velocity profiles are similar. The appropriate boundary conditions are:

at $y=0: u=0$ i.e., at $\eta=0: f^{\prime}=0$

at $\mathrm{y}=0: \mathrm{v}=0$ i.e., at $\eta=0: \mathrm{f}=0$

for large $y: u \rightarrow u_{1}$ i.e., for large $\eta: f^{\prime} \rightarrow 1$

To solve eq (3), we nondimensionlize the temperature according to the following

$$
\theta=\frac{T_{w}-T}{T_{w}-T_{1}}=1-\frac{T-T_{1}}{T_{w}-T_{1}}
$$

The assumptions that the temperature profiles are similar is equivalent to assuming that $\theta$ depends only on the similarity variable, $\eta$, because the thermal boundary layer thickness is also of the order $x / \sqrt{\operatorname{Re}_{x}}$.
The energy eq (3) can be written in terms of $\theta$ as $\left(T_{1}\right.$ is constant)

$$
\begin{aligned}
& -u \frac{\partial}{\partial x}\left[(1-\theta)\left(T_{w}-T_{1}\right)\right]+v \frac{\partial \theta}{\partial y}\left(T_{w}-T_{1}\right) \\
= & \frac{v}{\operatorname{Pr}} \frac{\partial^{2} \theta}{\partial y^{2}}\left(T_{w}-T_{1}\right)
\end{aligned}
$$

The boundary conditions are then

$$
\begin{aligned}
& y=0: \theta=0 \\
& y \text { large: } \theta \rightarrow 1
\end{aligned}
$$

Using the relations for the velocity components previously derived, eq (19) gives

$$
\begin{gathered}
f^{\prime} \frac{\partial \theta}{\partial \eta} \frac{\partial \eta}{\partial x}-\frac{n f^{\prime}(1-\theta)}{x}+\left[\frac{1}{2} \sqrt{\frac{v}{u_{1} x}}\left(n f^{\prime}-f\right)\right] \frac{\partial \theta}{\partial \eta} \frac{\partial \eta}{\partial y} \\
=\frac{1}{\operatorname{Pr}} \frac{v}{u_{1}} \frac{\partial^{2} \theta}{\partial \eta^{2}}\left[\frac{\partial \eta}{\partial y}\right]^{2}
\end{gathered}
$$

After rearrangement, it becomes

$$
\theta^{\prime \prime}+n \operatorname{Pr} f^{\prime}(1-\theta)+\frac{\operatorname{Pr}}{2} \theta^{\prime} f=0
$$

with the following boundary conditions

$$
\begin{aligned}
& \eta=0: \theta=0 \\
& \eta \text { large: } \theta \rightarrow 1
\end{aligned}
$$

Thus the energy eq (3) has been reduced to an ordinary differential equation (21). This confirms the assumptions that temperature velocity profiles are similar.

\section{SOLUTION PROCEDURE}

Eqs (16) and (21) are nonlinear ordinary differential equations for the velocity and temperature functions, $f^{\prime}$ and $\theta$, and are independent of of each other. Eq (16) is solved first and then eq (21). No analytic solution is known, so numerical integration is necessary. There are two unknown initial values at the wall. One must find the proper values of $f^{\prime \prime}(0)$ and $\theta^{\prime}(0)$ which cause the velocity and temperature to their respective free stream values for large $\eta$. The Prandtl number, $\operatorname{Pr}$ and the exponent, $\mathrm{n}$ are parameters in the second case.

\subsection{Reduction of Equations to First-Order System}

This is done easily by defining new variables:

$$
z_{1}=f
$$




$$
\begin{gathered}
z_{2}=z_{1}^{\prime}=f^{\prime} \\
z_{3}=z_{2}^{\prime}=z_{1}^{\prime \prime}=f^{\prime \prime} \\
z_{3}^{\prime}=z_{2}^{\prime \prime}=z_{1}^{\prime \prime \prime}=f^{\prime \prime \prime}=-\frac{1}{2} f f^{\prime \prime}=-\frac{1}{2} z_{1} z_{3} \\
z_{4}=\theta \\
z_{5}=z_{4}^{\prime}=\theta^{\prime} \\
z_{5}^{\prime}=z_{4}^{\prime \prime}=\theta^{\prime \prime}=-n \operatorname{Pr} z_{2}\left(1-z_{4}\right)+\frac{\operatorname{Pr}}{2} z_{1} z_{5}
\end{gathered}
$$

Therefore from eqs (16) and (21), we get the following set of differential equations

$$
\begin{gathered}
z_{1}^{\prime}=f^{\prime} \\
z_{2}^{\prime}=z_{1}^{\prime \prime}=f^{\prime \prime} \\
z_{3}^{\prime}=z_{2}^{\prime \prime}=z_{1}^{\prime \prime \prime}=f^{\prime \prime \prime}=-\frac{1}{2} f f^{\prime \prime}=-\frac{1}{2} z_{1} z_{2} \\
z_{4}^{\prime}=\theta^{\prime} \\
z_{5}^{\prime}=\theta^{\prime \prime}=-n \operatorname{Pr} z_{2}\left(1-z_{4}\right)+\frac{\operatorname{Pr}}{2} z_{1} z_{5}
\end{gathered}
$$

with the following boundary conditions:

$$
\begin{gathered}
z_{1}(0)=f(0)=0 \\
z_{2}(0)=z_{1}^{\prime}(0)=f^{\prime}(0)=0 \\
z_{2}(\infty)=z_{1}^{\prime}(\infty)=f^{\prime}(\infty)=1 \\
z_{4}(0)=\theta(0)=0 \\
z_{4}(\infty)=\theta(\infty)=1
\end{gathered}
$$

Eq (16) is third-order and is replaced by three first-order equations, whereas eq (21) is second-order and is replaced with two first-order equations.

\subsection{Solution to Initial Value Problems}

To solve eqs (24), we denote the two unknown initial values by $\mathrm{a}_{1}$ and $\mathrm{a}_{2}$, the set of initial conditions is then:

$$
z_{1}(0)=f(0)=0
$$

$$
\begin{gathered}
z_{2}(0)=z_{1}^{\prime}(0)=f^{\prime}(0)=0 \\
z_{3}(0)=z_{2}^{\prime}(0)=z_{1}^{\prime \prime}(0)=f^{\prime \prime}(0)=a_{1} \\
z_{4}(0)=\theta(0)=0 \\
z_{5}(0)=z_{4}^{\prime}(0)=\theta^{\prime}(0)=a_{2}
\end{gathered}
$$

If eqs (24) are solved with adaptive Runge-Kutta method using the initial conditions in eq (26), the computed boundary values at $\eta=\infty$ depend on the choice of $\mathrm{a}_{1}$ and $\mathrm{a}_{2}$ respectively. We express this dependence as

$$
\begin{aligned}
& z_{2}(\infty)=z_{1}^{\prime}(\infty)=f^{\prime}(\infty)=f_{1}\left(a_{1}\right) \\
& z_{4}(\infty)=\theta(\infty)=f_{2}\left(a_{2}\right)
\end{aligned}
$$

The correct choice of $a_{1}$ and $a_{2}$ yields the given boundary conditions at $\eta=\infty$; that is, it satisfies the equations

$$
\begin{aligned}
& f_{1}\left(a_{1}\right)=1 \\
& f_{2}\left(a_{2}\right)=1
\end{aligned}
$$

These nonlinear equations can be solved by the NewtonRaphson method. A value of 6 is fine for infinity, even if we integrate further nothing will change.

\subsection{Program Details}

This section describes a set of Matlab routines for the solution of eqs (24) along with the boundary conditions (26). They are listed in Table 1.

Table 1 A set of Matlab routines used sequentially to solve Equations (24).

\begin{tabular}{|l|l|}
\hline $\begin{array}{l}\text { Matlab } \\
\text { code }\end{array}$ & Brief Description \\
\hline deqs.m & Defines the differential equations (24). \\
\hline incond.m & $\begin{array}{l}\text { Describes initial values for integration, } \mathrm{a}_{1} \\
\text { and } \mathrm{a}_{2} \text { are guessed values, eq (26) }\end{array}$ \\
\hline runKut5.m & $\begin{array}{l}\text { Integrates as initial value problem using } \\
\text { adaptive Runge-Kutta method. }\end{array}$ \\
\hline residual.m & $\begin{array}{l}\text { Provides boundary residuals and } \\
\text { approximate solutions. }\end{array}$ \\
\hline $\begin{array}{l}\text { newtonraph } \\
\text { son.m }\end{array}$ & $\begin{array}{l}\text { Provides correct values a and a } \mathrm{a}_{2} \text { using } \\
\text { approximate solutions from residual.m }\end{array}$ \\
\hline runKut5.m & $\begin{array}{l}\text { Again integrates eqs (24) using correct } \\
\text { values of } \mathrm{a}_{1} \text { and } \mathrm{a}_{2} .\end{array}$ \\
\hline
\end{tabular}

The final output of the code runKut5.m gives the tabulated values of $f, f^{\prime}, f^{\prime \prime}$ as function of $\eta$ for velocity profile, and $\theta$ and $\theta^{\prime}$ as function of $\eta$ for various values of Prandtl number and $\mathrm{n}$. 


\section{INTERPRETATION OF THE RESULTS}

\subsection{Dimensionless Velocity and Temperature Profiles}

Physical quantities are related to the dimensionless functions $f$ and $\theta$ through eqs (7), (11), (12) and (18). ${ }^{f}$ and $\theta$ are now known. The complete numerical solution of eq (24) for velocity profile is given in Table 2 . From this we can find all the flow parameters of interest to flat plate.

Table 2 Computed values of $f^{\prime}, f^{\prime}$, and $f^{\prime \prime}$

\begin{tabular}{|c|c|c|c|}
\hline$\eta$ & $f$ & $f^{\prime}$ & $f^{\prime \prime}$ \\
\hline 0 & 0 & 0 & 0.3326 \\
\hline 0.1000 & 0.0017 & 0.0333 & 0.3326 \\
\hline 0.7064 & 0.0829 & 0.2344 & 0.3293 \\
\hline 1.3108 & 0.2839 & 0.4293 & 0.3125 \\
\hline 1.9050 & 0.5923 & 0.6049 & 0.2751 \\
\hline 2.4914 & 0.9913 & 0.7504 & 0.2185 \\
\hline 3.0892 & 1.4750 & 0.8611 & 0.1514 \\
\hline 3.5750 & 1.9091 & 0.9220 & 0.1004 \\
\hline 4.0103 & 2.3187 & 0.9573 & 0.0634 \\
\hline 4.4487 & 2.7436 & 0.9788 & 0.0364 \\
\hline 4.8572 & 3.1459 & 0.9900 & 0.0200 \\
\hline 5.2529 & 3.5390 & 0.9959 & 0.0103 \\
\hline 5.6481 & 3.9332 & 0.9988 & 0.0049 \\
\hline 6.0000 & 4.2849 & 1.0000 & 0.0024 \\
\hline
\end{tabular}

Fig 3 shows a plot of $f^{\prime}, f^{\prime}$, and $f^{\prime \prime}$ and Fig 4 compares of the profile $f^{\prime}$ with the experiments of Liepmann [12]. The agreement is excellent.

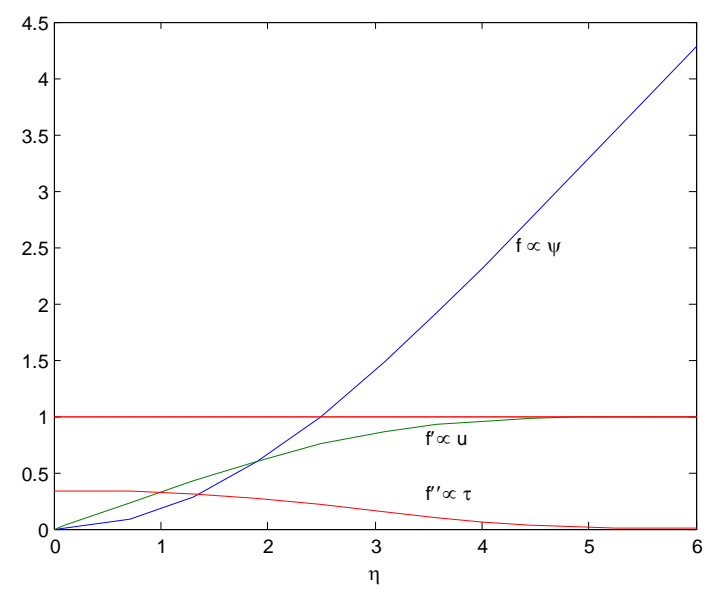

Fig. 3 Solutions $f, f^{\prime}$ and $f^{\prime \prime}$

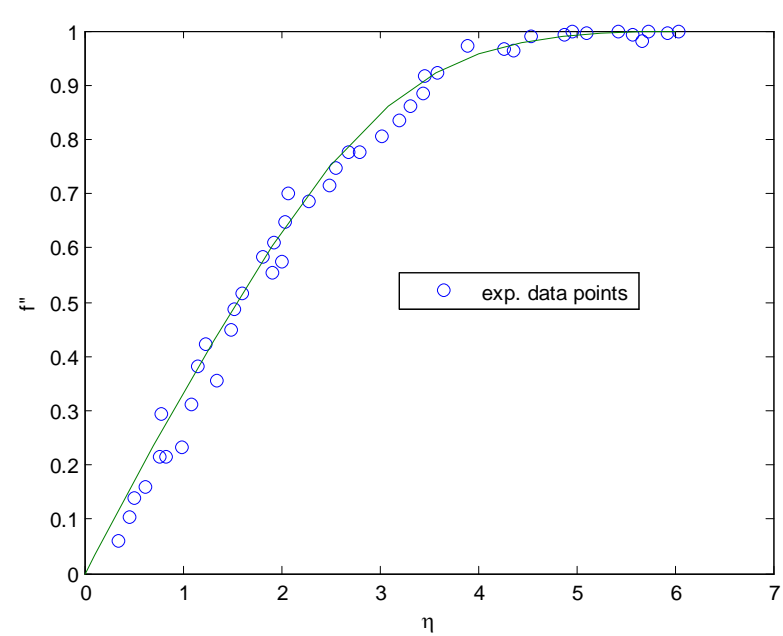

Fig. 4 Comparison of $f^{\prime}$ with experiments of Liepman Some computed values of $\left.\theta^{\prime}\right|_{\eta=0}$ are given in Table 3 and some typical variations of $\left.\theta^{\prime}\right|_{\eta=0}$ with $\mathrm{n}$ for various values of $\operatorname{Pr}$ obtained from the code is shown in Fig 5.

Table 3 Computed values of $\left.{ }^{\prime}\right|_{\eta=0}$
\begin{tabular}{|l|l|l|l|}
\hline \multirow{4}{*}{$\mathrm{m}$} & $\left.\theta^{\prime}\right|_{\eta=0}$ & \multicolumn{2}{l|}{} \\
\cline { 2 - 4 } & $\operatorname{Pr}$ & \multicolumn{3}{l|}{} \\
\cline { 2 - 4 } & 0.7 & 10 & 30 \\
\hline 0.00 & 0.2927 & 0.7281 & 1.0517 \\
\hline 0.25 & 0.3569 & 0.8811 & 1.2720 \\
\hline 0.50 & 0.4059 & 0.9979 & 1.4402 \\
\hline 0.75 & 0.4460 & 1.0937 & 1.5783 \\
\hline 1.00 & 0.4803 & 1.1757 & 1.6965 \\
\hline 1.25 & 0.5150 & 1.2480 & 1.8006 \\
\hline 1.50 & 0.5376 & 1.3129 & 1.8941 \\
\hline
\end{tabular}

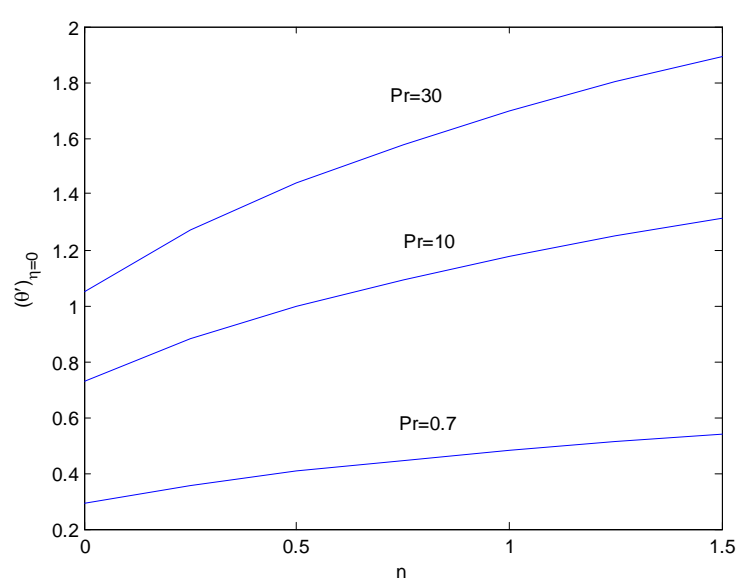

Fig 5 Variation of $\left.\theta^{\prime}\right|_{\eta=0}$ with $\eta$ for various values of $\operatorname{Pr}$. 
Variations of $\theta$ with $\eta$ for various values of $\operatorname{Pr}$ with exponent, $\mathrm{n}$ as parameter obtained from the code are shown in Fig 6a, 6b and $6 \mathrm{c}$.

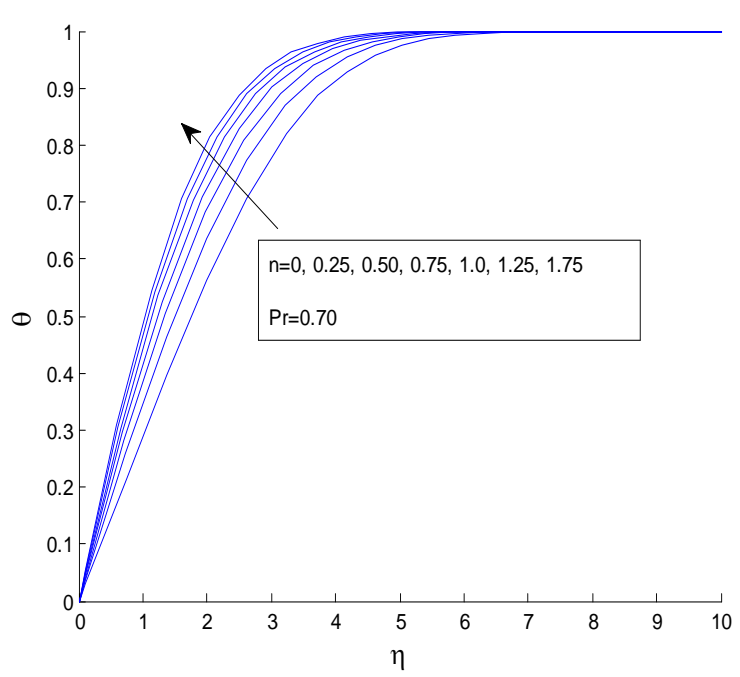

Fig. 6a Solution of $\theta$ for $\operatorname{Pr}=0.70$

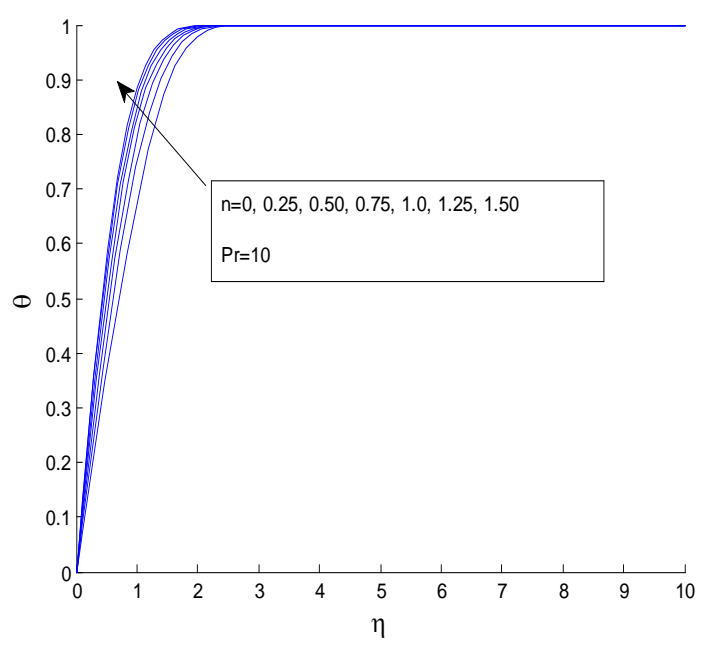

Fig. 6b Solution of $\theta$ for $\operatorname{Pr}=10$

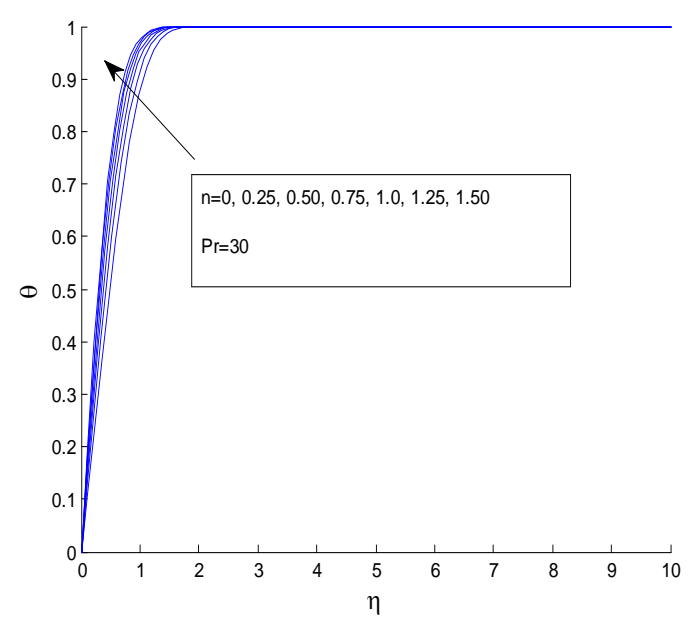

Fig. 6c Solution of $\theta$ for $\operatorname{Pr}=30$

\subsection{Flow and Heat Transfer Parameters}

Besides the velocity and temperature distributions, it is often desirable to compute other physically important quantities (for example, shear stress, drag, heat-transfer-rate) associated with the convection flow.

The boundary layer thickness, $\delta$, is defined as the value of $y$ at which $\mathrm{u}=0.99 \mathrm{u}_{1}$. Fig 5 shows that $\mathrm{u}=0.99 \mathrm{u}_{1}$, i.e., $f^{\prime}=0.99$ when $\eta=5$. From (7)

$$
\delta \sqrt{\frac{u_{1}}{v x}}=5
$$

i.e.,

$$
\frac{\delta}{x}=\frac{5}{\sqrt{\mathrm{Re}_{x}}}
$$

From eq (14), wall shear stress may be expressed as

$$
\tau_{s}=\left.\mu \frac{\partial u}{\partial y}\right|_{y=0}=\left.\mu u \sqrt{\frac{u_{1}}{v x}} \frac{d^{2} f}{d \eta^{2}}\right|_{\eta=0}
$$

Hence from Table 1

$$
\tau_{s}=0.3326 u_{1} \sqrt{\frac{\rho \mu u_{1}}{x}}
$$

The local friction coefficient is then

$$
C_{f, x}=\frac{\tau_{s}}{\rho u_{1}^{2} / 2}=0.665 \sqrt{\operatorname{Re}_{x}}
$$

The heat transfer rate at the wall is given by

$$
q_{w}=-\left.k \frac{\partial T}{\partial y}\right|_{y=0}
$$

Hence, using eq (18)

$$
\frac{q_{w}}{k\left(T_{w}-T_{1}\right)}=\left.\frac{\partial \theta}{\partial y}\right|_{y=0}=\left.\frac{\partial \theta}{\partial \eta}\right|_{\eta=0} \frac{\partial \eta}{\partial y}
$$

i.e.,

$$
\frac{q_{w} x}{k\left(T_{w}-T_{1}\right)}=\left.\theta\right|_{\eta=0} \sqrt{\operatorname{Re}_{x}}
$$


i.e.,

$$
N u_{x}=\left.\theta^{\prime}\right|_{\eta=0} \sqrt{\operatorname{Re}_{x}}
$$

From (34), the heat flux $\mathrm{q}_{\mathrm{w}}$ can be written as

$$
\frac{q_{w}}{k\left(T_{w}-T_{1}\right)}=\left.\frac{\partial \theta}{\partial \eta}\right|_{\eta=0} \sqrt{\frac{u_{1}}{v x}}
$$

Or

$$
\begin{gathered}
q_{w}=\left.\frac{\partial \theta}{\partial \eta}\right|_{\eta=0} k\left(T_{w}-T_{1}\right) \sqrt{\frac{u_{1}}{v x}} \\
=\left.\frac{\partial \theta}{\partial \eta}\right|_{\eta=0} k\left(C x^{n}\right) \sqrt{\frac{u_{1}}{v x}}=\left.\frac{\partial \theta}{\partial \eta}\right|_{\eta=0} k C \sqrt{\frac{u_{1}}{v}} \frac{x^{n}}{x^{0.5}}
\end{gathered}
$$

For given values of Pr and $\mathrm{n},\left.\theta^{\prime}\right|_{\eta=0}$ is fixed. So, it is evident from eq (36) that the heat flux from the plate will be uniform when $\mathrm{n}=0.5$.

\section{CONCLUSION}

In the present numerical simulation, laminar convection flow and heat transfer over a non isothermal horizontal plate is presented. Details of the solution procedure of the nonlinear partial differential equations of flow are discussed. The computer codes are developed for this numerical analysis in Matlab environment. Velocity profile, and temperature profiles for Prandtl numbers of $0.7,10.0$ and 30.0 with exponent $\mathrm{n}=0,0.025,0.50,0.75,1.0,1.25$ and 1.50 are computed using these codes. The computed and experimental velocity and temperature distributions are in very good agreement with results published in literatures. Flow and heat transfer parameters (giving physically important quantities such as shear stress, drag, heat-transfer-rate) are derived. A good agreement between the present results and the past indicates that the developed numerical simulation as an efficient and stable numerical scheme in natural convection.

\section{REFERENCES}

[1]. Blasius, H., "Grenzschichten in Flussikeiten mitkleiner Reibung”, Z. Angew,Math. Phys., vol. 56, pp. 1-37, 1908 [English translation in NACA Technical Memo. 1256].

[2]. Meksyn, D., "New Methods in Laminar Boundary Layer Theory", Pergamon, London, 1961.

[3]. Rosenhead, L. (ED), "Laminar Boundary Layers", Oxford Univ. Press, London, 1963.

[4]. Hansen, A. G., "Similarity Analysis of Boundary Value Problems in Engineering", Prentice-Hall, Englewood Cliffs, N. J., 1964.

[5]. Bejan, A., Heat Transfer, John Wiley, New York, 1993.

[6]. Sachdev, P. L., "Self-Similarity and Beyond: Exact Solutions of Nonlinear Problems", CRC Press, Boca Ratton, Fla, 2000
[7]. Incropera, F.P. and DeWitt D.P., Introduction to Heat Transfer, Fourth edition, John Wiley, New York, 2002.

[8]. Çengel, Y.A., Heat Transfer, Second edition, McGrawHill, New York, 2003.

[9]. Lienhard IV, J.H. and Lienhard V, J.H., A Heat Transfer Textbook, Phlogiston Press, Cambridge, MA, 2003.

[10]. Nellis, G. and Klein, S., Heat Transfer, Cambridge University Press, London, UK, 2008.

[11]. Mitra A., "Numerical Simulation on Laminar FreeConvection Flow and Heat Transfer Over an Isothermal Vertical Plate," International Journal of Research in Engineering \& Technology, 04, 2015, pp 488-494.

[12]. Leipmann, H. W., "Investigation on Laminar BoundaryLayer Stabilty and Transition on Carved Boundaries, " NACA Wartime Report W107 (ACR3H30), 1943 [see also NACA Technical Memo. 1196 (1947) and NACA Report 890 (1947)]. 